\title{
Detección de Escherichia Coli productor de toxina Shiga en vísceras e animales bovinos y pollos destinadas para el consumo humano \\ Detection of Escherichia coli Shiga toxin-producing in viscera of animals bovine and chicken intended for human consumption
}

\author{
Zotta Claudio Marcelo ${ }^{1 *}$, Lavayén Silvina ${ }^{1}$, Nario Flavia $^{2}$, Piquín Andrea ${ }^{2}$
}

\section{Palabras clave: \\ Escherichia coli \\ productor de toxina Shiga, \\ síndrome urémico hemolítico, \\ serotipo O157:H7, \\ vísceras, \\ enfermedades transmitidas por \\ alimentos.}

\section{J. Selva Andina Res. Soc.} 2016; 7(1):2-9.

\section{Historial del artículo.}

Recibido junio, 2015.

Devuelto enero 2016

Aceptado febrero, 2016

Disponible en línea, febrero, 2016.

Editado por:

Selva Andina

Research Society

\section{Resumen}

Escherichia coli productor de toxina Shiga (STEC) está asociado a enfermedades transmitidas por alimentos (ETA). Puede causar diarrea sanguinolenta, colitis hemorrágica, síndrome urémico hemolítico y púrpura trombocitopénica trombótica. El objetivo del estudio consistió en detectar la presencia de STEC en muestras de vísceras (menudencias) de animales bovinos y pollos destinados para el consumo humano.

Entre 2008-2009 se procesaron 76 muestras de vísceras de animales bovinos y 22 muestras de vísceras de pollo y se les realizó, como técnica de tamizaje, la reacción en cadena de la polimerasa (PCR) múltiple para la detección de genes codificantes para los factores de virulencia: toxina Shiga $\left(s t x_{1}, s t x_{2}\right)$ y el gen $r f b_{0157}$ que codifica para el lipopolisacárido capsular LPS O157.

Las muestras de vísceras bovinas presentaron $84.2 \%$ de desarrollo para bacterias coliformes. Estos aislamientos no presentaron ningún factor de virulencia que los caracterice como STEC o como Escherichia coli O157. Las muestras de menudencias de pollos presentaron $95.5 \%$ de desarrollo para bacterias coliformes, siendo negativa la presencia de genes que codifican para las toxinas Shiga 1 y $2\left(s t x_{1}, s t x_{2}\right)$ y el gen $r f b_{0157}$.

Si bien en este trabajo no se detectó STEC, la presencia de bacterias coliformes en las muestras estudiadas hace que deba considerarse a estos alimentos como potencialmente riesgosos para consumirlos insuficientemente cocidos con la consiguiente posibilidad de presentación de ETA.

(C) 2016. Journal of the Selva Andina Research Society. Bolivia. Todos los derechos reservados.

Abstract
Escherichia coli producing-Shiga toxin (STEC) is associated with foodborne illness (ETA). It can cause bloody
diarrhea, hemorrhagic colitis, hemolytic uremic syndrome and thrombotic thrombocytopenic purpura.
The aim of the study was to detect the presence of STEC in samples of organs (offal) of bovine animals and
chicken intended for human consumption.
Between 2008-2009, 76 samples bovine entrails and 22 chicken viscera samples, were processed and underwent,
as screening technique, the polymerase chain reaction (PCR) for detection of multiple genes coding for the factors
virulence: Shiga toxin (stx $x_{1}$, st $_{2}$ ) and $r f b_{\text {O157 }}$ gene coding for capsular O157 lipopolysaccharide LPS.
Samples from bovine offal development showed $84.2 \%$ for coliform bacteria. These isolates showed no virulence
factor that characterized as STEC or Escherichia coli O157. The chicken offal samples showed $95.5 \%$ of devel-
opment for coliform bacteria, being negative for the presence of genes encoding the Shiga toxins 1 and 2 (stx
stx $x_{2}$ ) and $r f b_{0157}$ gene.




\begin{tabular}{l|l}
\hline Key words: & $\begin{array}{l}\text { While this work does not STEC was detected, the presence of coliform bacteria in the samples studied makes } \\
\text { these foods should be considered as potentially hazardous to consume undercooked with the consequent possibil- } \\
\text { ity of filing ETA. }\end{array}$ \\
$\begin{array}{l}\text { Escherichia coli } \\
\text { producing-Shiga toxin, } \\
\text { hemolytic uremic syn- } \\
\text { drome, } \\
\text { serotype O157:H7, } \\
\text { viscera, } \\
\text { foodborne illness. }\end{array}$ & C 2016. Journal of the Selva Andina Research Society. Bolivia. All rights reserved. \\
\hline
\end{tabular}

\section{Introducción}

Escherichia coli productor de toxina Shiga (STEC) está asociado a enfermedades transmitidas por alimentos (ETA). Puede causar desde diarrea sanguinolenta (DS) hasta enfermedades severas en el hombre, como colitis hemorrágica $(\mathrm{CH})$, síndrome urémico hemolítico (SUH) y púrpura trombocitopénica trombótica (PTT) (Mead \& Griffin 1998, Karmali 1989).

Argentina presenta el índice más alto de casos de SUH en el mundo (más de 400 casos anuales) constituyéndose en una enfermedad endémica para el país y resultando la primera causa pediátrica de insuficiencia renal aguda (Servicio FisiopatogeniaInstituto Nacional de Enfermedades Infecciosas \& Comité de Nefrología 2007).

El SUH se transmite principalmente por ingesta de alimentos contaminados con STEC, siendo el serotipo 0157:H7 el más reconocido en el mundo (World Health Organization 1997, Rivas et al. 2003, Oteiza et al. 2006). Otras formas de transmisión incluyen el contacto directo del hombre con los animales, la contaminación cruzada durante la preparación de alimentos, y la transmisión persona a persona por la ruta fecal-oral.

El ganado bovino y especialmente los animales jóvenes (terneros) actúan como reservorio principal de esta bacteria, portándola en su flora intestinal (Ørskov et al. 1987, Beutin et al.1993, Chapman et al. 1993, Wells et al. 1991, Parma et al. 2000,
Cobbold \& Desmarchelier 2001, Meichtri et al. 2004).

Además de los bovinos, este microorganismo ha sido aislado del contenido intestinal de diversos animales, tales como ovinos, caprinos, cerdos, perros, gatos y pollos (Beutin et al.1993, Chapman et al. 1993, Bülte et al. 1990, Griffin \& Tauxe 1991, Doyle 1997, Ramachandran et al. 2001, Caprioli et al. 2005).

Durante las operaciones de carnización, fundamentalmente el desollado y la evisceración, pueden llegar a las superficies de las canales y de las vísceras estos microorganismos procedentes de la flora intestinal del animal.

Distintas vísceras y órganos bovinos (denominadas "menudencias" según el artículo 252 del Código Alimentario Argentino) como corazón, timo (molleja), hígado, bazo (pajarilla), mondongo (rumen, librillo y redecilla), cuajar de los rumiantes, intestino delgado (chinchulines), recto (tripa gorda), riñones, pulmones (bofe), encéfalo (sesos), médula espinal (filet), criadillas, páncreas, ubre suelen formar parte tradicionalmente de la "parrillada", destinada al consumo humano, o consumidos en distintas preparaciones.

Asimismo la ingesta de vísceras o menudencias de pollo (hígado y mollejas, entre otros) forma parte de la cultura alimentaria de muchos países latinoamericanos, debido a su bajo costo y alto contenido proteínico. 
En Argentina la comercialización de menudencias (también llamadas achuras) en el mercado interno se realiza a través de la compra de materia prima a frigoríficos (consumeros o exportadores) por operadores denominados achureros y/o directamente por supermercados (Ricci 2012).

Debido a la mayor cantidad de glucógeno y menor cantidad de grasas de revestimiento, las menudencias en general resultan más fácilmente alterables y difíciles de manejar que la carne contenida en las medias reses (Ockerman \& Hansen 1994) por lo tanto una vez faenadas debe ser rápida y adecuadamente refrigeradas.

$\mathrm{Su}$ vida útil depende de las condiciones higiene durante el faenado, rapidez en el tratamiento de refrigeración y/o congelación, y del transporte, distribución y venta de estos productos.

Experiencias realizadas por la Estación Experimental Agronómica de Texas (TAES), en colaboración con el Departamento de Ciencias y de Educación del Ministerio de Agricultura de EEUU, mediante ensayos microbiológicos realizados sobre hígados, lenguas, riñones y corazones mostraron que las menudencias si eran rápida y adecuadamente refrigeradas no presentaban desarrollo microbiano importante durante un almacenamiento de 5 días en condiciones constantes de refrigeración de $1.5^{\circ} \mathrm{C}$. Cuando los hígados y riñones eran expuestos durante 6 ó $12 \mathrm{~h}$ a una temperatura ambiente excesiva (del orden de $30{ }^{\circ} \mathrm{C}$ ), antes de la congelación, la tasa microbiana aumentaba considerablemente.

Por lo expuesto en cuanto a las propiedades intrínsecas de estos alimentos, a las condiciones requeridas para su adecuado procesamiento y a los hábitos de consumo de los mismos se hace necesario investigar la presencia de esta bacteria en estos tipos de productos listos para la venta al consumidor.
El objetivo del estudio consistió en detectar la presencia de STEC en muestras de vísceras (menudencias) de animales bovinos y pollos destinadas para el consumo humano con el fin de aumentar el conocimiento sobre la circulación de STEC en otras posibles fuentes de contagio que permita llevar a cabo acciones de prevención para la infección por este microorganismo asociado a la presentación de Síndrome Urémico Hemolítico.

\section{Materiales y métodos}

Se realizó un estudio descriptivo de corte transversal para determinar la presencia/ausencia de STEC. Las variables sometidas a estudio fueron: especie de animal (bovino, pollo), tipo de vísceras, desarrollo/ausencia de bacterias coliformes, presencia/ausencia de STEC.

La muestra para la realización del trabajo resultó ser por conveniencia por razones de logística.

Durante el período 2008-2009 se estudiaron: 76 muestras de vísceras de animales bovinos (centro de entraña, corazón, entraña, hígado, chinchulines, mollejas, riñones, sesos y tripa gorda) que provenían de varias sucursales de una cadena de supermercados las cuales tenían un proveedor común y 22 muestras de vísceras de pollo (hígado, corazón y panza) provenientes de un frigorífico faenador de aves. Fuerón procesadas inicialmente en el Laboratorio de Control de Calidad de dicha cadena de supermercados.

Para su procesamiento se tomó $20 \mathrm{~g}$ de cada muestra y se le agregó $200 \mathrm{~mL}$ de agua peptonada bufferada (Britania, Ciudad Autónoma de Buenos Aires, Argentina) incubándose a $37{ }^{\circ} \mathrm{C}$ durante $6 \mathrm{~h}$. Luego se tomó $1 \mathrm{~mL}$ de esa suspensión con pipeta estéril y se colocó en un tubo con $9 \mathrm{~mL}$ de caldo McConkey (Britania, Ciudad Autónoma de Buenos Aires, Ar- 
gentina) incubándose a $37{ }^{\circ} \mathrm{C}$ durante $18-24$ h. Posteriormente para el aislamiento se sembró en placas de petri con agar Mac Conkey (Britania, Argentina) y en Medio cromogénico E. coli (Oxoid, Basingstoke, Reino Unido) y se incubó a $37{ }^{\circ} \mathrm{C}$ durante $18-24$ horas de acuerdo al protocolo de primoaislamiento e identificación utilizado (Blanco et al. 1996).

Posteriormente las placas con desarrollo de bacterias coliformes fueron derivadas al Servicio de Bacteriología del Departamento Laboratorio de Diagnóstico y Referencia Las placas de cultivo sembradas fueron enviadas al Servicio de Bacteriología del Laboratorio de Diagnóstico y Referencia del Instituto Nacional de Epidemiología "Dr. Juan H. Jara" ANLIS “Dr. Carlos G. Malbrán”, en donde se realizó a partir de la zona de confluencia y de 10 colonias elegidas al azar de las placas de primoaislamiento (según protocolo estandarizado) la detección de los genes de toxina Shiga $s t x_{1}, s t x_{2}$ y $r f b_{0157}$, mediante técnica de reacción de la polimerasa en cadena (PCR) múltiple (Leotta et al. 2005). Las colonias seleccionadas se suspendieron en $150 \mathrm{~L}$ de solución de tritón X-100 (Promega, Madison, WI, EE.UU.) al $1 \%$ en buffer TE $1 X$. Se centrifugaron a 10000 rpm durante 5 min luego de hervir en baño de agua a $100{ }^{\circ} \mathrm{C}$ durante $15 \mathrm{~min}$. El extracto de ADN se conservó a $4{ }^{\circ} \mathrm{C}$ para ser utilizado como templado.

Para realizar la PCR múltiple se utilizaron tres pares de oligonucleótidos iniciadores para amplificar fragmentos de los genes $s t x_{1}$, stx $x_{2}$ y $r f b_{0157}$ : stx la (5'- GAAGAGTCCGTGGGATTACG-3'), stx1b (5'-AGCGATGCAGCTATTAATAA-3'), stx2a (5'-TTAACCACACCCCACCGGGCAGT-3'), stx2b (5'- GCTCTGGATGCATCTCTGGT-3'), O157F (5'- CGGACATCCATGTGATATGG-3') y O157R (5'- TTGCCTATGTACAGCTAATCC-3'), cuyos tamaños de los fragmentos de amplificación 5 fueron 130,346 y $259 \mathrm{pb}$ respectivamente. Se utilizaron 50 L finales de mezcla de reacción de PCR, conteniendo 5 L de Buffer PCR 10X (Invitrogen Life Technologies, Brasil), $2 \mathrm{~L}$ de mezcla de dNTPs $2.5 \mathrm{mM}$ (Promega), $1.5 \mathrm{~L}$ de $\mathrm{Cl}_{2} \mathrm{Mg} 50$ Mm (Invitrogen), 1 L del par de oligonucleótidos iniciadores Stx1 $0.1 \mathrm{nmol} / \mathrm{L}$ (Invitrogen), $0.2 \mathrm{~L}$ de los pares de oligonucleótidos iniciadores Stx2 0.1 nmol/ L (Invitrogen), $0.3 \mathrm{~L}$ de los pares de oligonucleótidos iniciadores $01570.1 \mathrm{nmol} / \mathrm{L}$ (Invitrogen), 0.2 L de $T a q$ polimerasa $5 \mathrm{U} / \mathrm{mL}$ (Invitrogen), 36.3 L de agua tridestilada estéril y finalmente 2 $\mathrm{L}$ de ADN templado. Como control positivo y negativo se utilizó el ADN templado de las cepas $E$. coli EDL933 O157:H7 stx1/stx2 y E. coli ATCC 25922 sin factores de virulencia, respectivamente. Además se utilizaron 50 L de mezcla de reacción de PCR sin ADN templado como control de sistema. Se utilizó un termociclador Multigene TC9600 (Labnet, Edison, NJ, EE.UU.). Las condiciones de amplificación fueron $94{ }^{\circ} \mathrm{C}$ por $5 \mathrm{~min}$, seguido de 30 ciclos a $94{ }^{\circ} \mathrm{C}$ por $30 \mathrm{seg}, 58{ }^{\circ} \mathrm{C}$ por $30 \mathrm{seg}$ y 72 ${ }^{\circ} \mathrm{C}$ por $30 \mathrm{seg}$. La extensión final fue a $72{ }^{\circ} \mathrm{C}$ por 2 min. Se agregaron 10 L de una solución de xilene cyanol $0.25 \%$ y glicerol en agua 30\% (Sigma, St Louis, EE.UU.) a 50 L del ADN amplificado; sembrándose 10 L en un gel de agarosa (Invitrogen) al $2 \%$ en buffer TAE $1 \mathrm{X}$ (Invitrogen) y los marcadores de peso molecular $100 \mathrm{bp}$ Molecular Rule (BioRad, Hércules, CA, EE.UU.) y Cienmarker (Biodynamics S.R.L., Buenos Aires, Argentina). Se realizó la corrida electroforética a $8 \mathrm{~V} / \mathrm{cm}$ (Labnet) durante $50 \mathrm{~min}$. Posteriormente el gel fue sumergido en una suspensión de bromuro de etidio 0.5 $\mathrm{g} / \mathrm{mL}$ (Promega) durante $3 \mathrm{~min}$. Para documentar el gel se utilizó un transiluminador TFX-20M (Vilbert Lourmat, Marne-la-Vallée Cédex, Francia). 
Se realizó el análisis descriptivo de variables en estudio mediante el uso del paquete estadístico informatizado Epi Info ${ }^{\mathrm{TM}}$ 3.5.4 y la asociación estadística de variables con el programa Epi Dat 3.1. (Centers for Disease Control and Prevention. 2010) Se utilizó el test de $\chi^{2}$ para datos independientes fijándose un nivel de significación estadística del $5 \%$ para el test.

\section{Resultados}

De las 98 muestras procesadas de vísceras, el 77.5\% (76/98) fueron de animales bovinos y el $22.5 \%$ (22/98) provenían de pollos.

Las muestras de origen bovino presentaron $84.2 \%$ (64/76) de desarrollo para bacterias coliformes. Estos aislamientos no demostraron, al aplicárseles la técnica de PCR múltiple, ningún factor de virulencia que los caracterice como STEC o como Escherichia coli $\mathrm{O} 157$.

Figura 1 Distribución porcentual por tipo de vísceras bovinas procesadas. INE - 2009. $(n=76)$

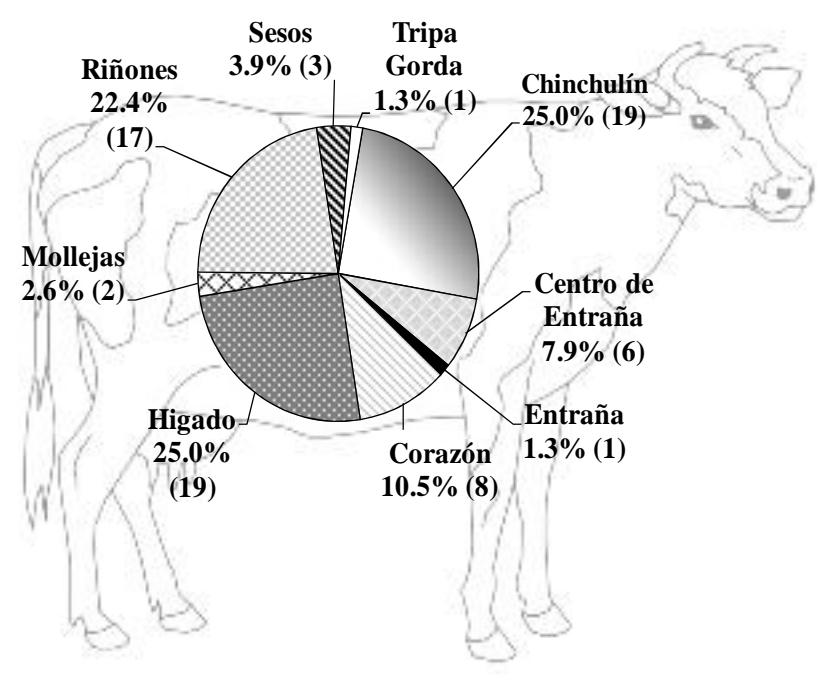

La distribución por tipo de vísceras bovinas procesadas se muestra en la Figura 1, La distribución porcentual de aislamientos de bacterias coliformes según tipo de muestras bovinas procesadas se muestra en la Figura 2.

En las muestras de menudencias de pollos trabajadas, desarrollaron bacterias coliformes en un $95.5 \%$ (21/22), siendo negativa la presencia de genes que codifican para las toxinas Shiga 1 y 2 (stx $x_{1}$ st $\left.x_{2}\right)$ como así también el gen $r f b_{0157}$ por la técnica de PCR múltiple en estos aislamientos.

Figura 2 Distribución porcentual de aislamientos de bacterias coliformes según tipo de muestras bovina procesadas. INE - 2009. $(n=76)$

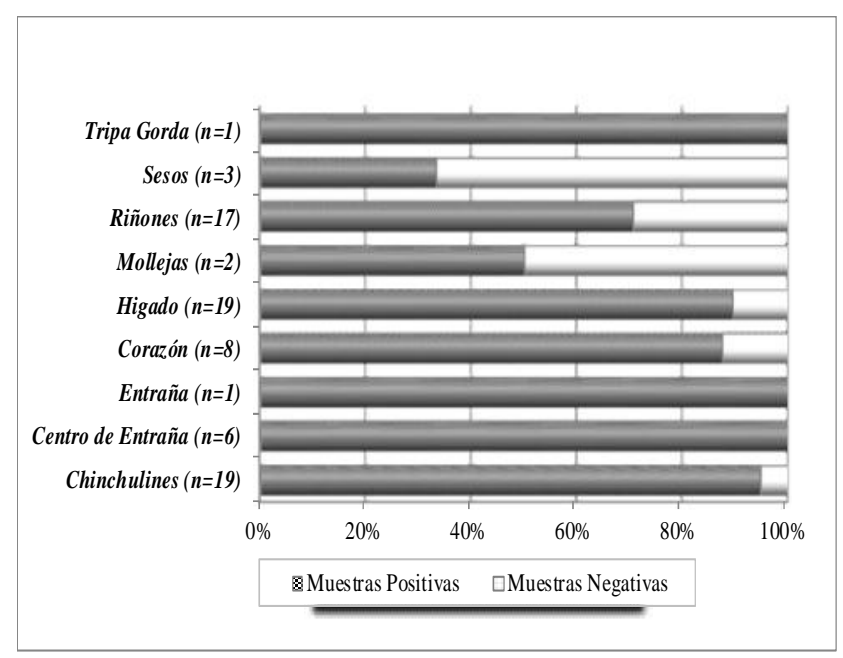

No se observó diferencia estadísticamente significativa $(\mathrm{p}=0.311)$ entre las muestras de origen bovino y las menudencias de pollo con la detección de bacterias coliformes.

\section{Discusión}

Si bien en este trabajo no se detectó STEC, la presencia de bacterias coliformes en las muestras estudiadas hace que deba considerarse a estos alimentos como potencialmente riesgosos para consumirlos insuficientemente cocidos con la consiguiente posibilidad de presentación de ETA, dado que menu- 
dencias como el hígado de vaca, molido y cocido, es uno de los alimentos recomendado por los pediatras para iniciar la dieta sólida de los lactantes y tanto los chinchulines y riñones son alimentos que habitualmente componen la tradicional parrillada para consumo humano.

Podría resultar paradójico que constituyéndose el ganado bovino, a través de la colonización de su lumen intestinal, como el principal reservorio de STEC, en este trabajo no se haya detectado este microorganismo en alimentos tales como chinchulines (intestino delgado del rumiante) ni tripa gorda (intestino grueso).

Diversas hipótesis podrían aplicarse a esta situación como la susceptibilidad de los animales a la colonización por STEC o la competencia de esta bacteria con el resto de la flora microbiana habitual del tubo intestinal de los bovinos.

No se halló literatura extensa sobre resultados de vigilancia de STEC en este tipo de vísceras (menudencias de animales bovinos y de pollos) destinadas para el consumo humano, aunque si se detectó STEC en morcillas (embutido cocido elaborado sobre la base de sangre de animales de consumo permitidos, recogida durante el degüello efectuado en buenas condiciones higiénicas y en recipientes perfectamente lavados, desfibrinada y filtrada, con el agregado o no de tocino, cuero de cerdo picado, sal y especias) (Oteiza et al. 2006). Este alimento en particular no se investigó en el trabajo porque a diferencia de las muestras de vísceras estudiadas, es considerado un producto que tiene un proceso de elaboración previa y que suele ser consumido sin tratamiento térmico posterior.

Cabe recordar que la carne fresca y la leche no pasteurizada son considerados los vehículos comunes de STEC, especialmente de la cepa O157:H7. La contaminación de la carne suele producirse durante 7 el sacrificio del animal y el faenado de la canal, como consecuencia de deficientes prácticas de higiene e inadecuadas normas higiénicas en los mataderos. De particular importancia son las fases de extracción de la piel, extracción de las vísceras y manipulación después del faenado, porque, de no controlarse debidamente, probablemente ocasionen la contaminación de la carne por las heces del animal.

La buena higiene a lo largo de todo el proceso de producción, elaboración y comercialización como así también una adecuada cocción de estos alimentos son fundamentales para prevenir enfermedades de carácter alimentario en la población.

El fortalecimiento de los sistemas nacionales de inocuidad de los alimentos encargados de la fiscalización a lo largo de toda la cadena de producción alimentaria, el accionar responsable de productores y elaboradores y la participación activa de los consumidores (capacitados en la adecuada preparación higiénica de los alimentos) permitiría gestionar de forma más eficaz el suministro de productos alimenticios inocuos para la población a fin de disminuir la morbi-mortalidad de estas enfermedades en la comunidad.

\section{Conflictos de intereses}

Los autores declaran que no existen conflictos de Interés.

\section{Agradecimientos}

Se agradece la colaboración de la Dra. Diana Gómez (MV, Bacterióloga Clínica e Industrial) en el desarrollo del presente trabajo 


\section{Literatura citada}

Beutin L, Geier D, Steinrück H, Zimmermann S, Scheutz F. Prevalence and some properties of verotoxin (Shiga-like toxin)-producing Eschericha coli in seven different species of healthy domestic animals. J Clin Microbiol. 1993; 31: 2483-2488.

Blanco JE, Blanco M, Blanco J, Alonso MP. Escherichia coli toxigénicos en alimentos y muestras clínicas de origen humano y animal. Patogénesis y epidemiología. Med Vet. 1996; 13: 207-221.

Bülte Von M, Montenegro MA, Helmuth R, Trupf T, Reuter G. Nachweis von Verotoxin-bildenden E. coli (VTEC) bei gesunden Rindern und Schweinen mit dem DNS-DNS-Koloniehybridi sierungsverfahren, Berl. Münch. Tierärztl Wsc hr. 1990; 103: 380-384.

Caprioli A, Morabito S, Brugère H, Oswald E. Enterohaemorrhagic Escherichia coli: emerging issues on virulence and modes of transmission. Vet Res. 2005; 36: 289-311.

Centers for Disease Control and Prevention. Program Epi Info ${ }^{\mathrm{TM}}$ version 3.5.4. Atlanta, United States of America. 2010. [Fecha de acceso 4 de diciembre de 2012]. URL Disponible en: http://www.cdc.gov/epiinfo/html/prevVersion.ht m.

Chapman PA, Siddons CA, Wright DJ, Norman P, Fox J, Crick E. Cattle as a possible source of verocytoxinproducing Escherichia coli $\mathrm{O} 157$ infections in man. Epidemiol Infect. 1993; 111: 439-47.

Cobbold R, Desmarchelier P. Characterisation and clonal relationships of Shiga-toxigenic Escherichia coli (STEC) isolated from Australian dairy cattle. Vet Microbiol. 2001; 79: 323-35.
Código Alimentario Argentino. Cap.V, Artículos: 247 al 519 - Alimentos Cárneos y Afines. [Fecha de acceso 4 de diciembre de 2012]. URL Disponible en: http:// www.anmat.gov.ar/alimentos/ codigoa/Capitulo_VI.pdf

Doyle MP, Zhao T, Meng J, Zhao S. Escherichia coli O157:H7. In: Doyle MP, Beuchat LR, Montville TJ, editors. Food Microbiology: fundamentals and frontiers. Washington: American Society for Microbiology; 1997. p 171-191.

Griffin PM, Tauxe RV. The epidemiology of infections caused by Escherichia coli, and the associated hemolytic uremic syndrome, Epidemiol Rev. 1991; 13: 60-98.

Instituto Nacional de Enfermedades InfecciosasAdministración Nacional de Laboratorios e Institutos de Salud "Dr. Carlos G. Malbrán”, Servicio de Fisiopatogenia/Sociedad Argentina de Pediatría-Comité de Nefrología. Buenos Aires; 2007.

Karmali MA. Infection by verotoxin-producing Escherichia coli. Clin Microbiol Rev. 1989; 2: 15-38.

Leotta GA, Chinen I, Epszteyn S, Miliwebsky E, Melamed I, Motter M, Ferrer M, Marey E, Rivas M. Validación de una técnica de PCR múltiple para la detección de Escherichia coli productor de toxina Shiga. Rev Argent Microbiol. 2005; 37: 1-10.

Mead PS, Griffin PM. Escherichia coli O157:H7. Lancet 1998; 352: 1207-12.

Meichtri L, Miliwebsky E, Gioffré A, Chinen I, Baschkier A, Chillemi G, et al. Shiga toxinproducing Escherichia coli in healthy young beef steers from Argentina: prevalence and virulen ce properties. Int $\mathbf{J}$ Food Microbiol. 2004; 96: 189-198.

Ockerman HW, Hansen CL. Industrialización de subproductos de Origen Animal; 1994. Editorial 
Acribia, S.A. Zaragoza, España. ISBN 10: 84200 0751X.

Ørskov F, Ørskov I, Villar JA. Cattle as reservoir of verotoxin-producing Escherichia coli O157:H7. Lancet 1987; 1:276.

Oteiza JM, Chinen I, Miliwebsky E, Rivas M. Isolation and characterization of Shiga toxinproducing Escherichia coli from precooked sausages (morcillas). Food Microbiology 2006; 23: 283-8.

Parma AE, Sanz ME, Blanco JE, Blanco J, Blanco M, Padola NL, et al. Virulence genotypes and serotypes of verotoxigenic Escherichia coli isolated from cattle and foods in Argentina. Eur $\mathbf{J}$ Epidemiol. 2000; 16: 757-62.

Ramachandran V, Hornitzky MA, Bettelheim KA, Walker MJ, Djordjevic SP. The common ovine Shiga toxin 2-contain ing Escherichia coli serotypes and human isolates of the same serotypes possess a Stx2d toxin type. J Clin Microbiol. 2001; 39: 1932-7.
Ricci OR. Achuras. Consumo y comercialización de menudencias enfriadas en Argentina. [Fecha de acceso 4 de diciembre de 2012]. URL Disponible en: http:// www.produccion-animal.com.ar/in formacion_tecnica/carne_y_subproduc tos/139Achuras.pdf).

Rivas M, Caletti MG, Chinen I, Refi SM, Roladan $\mathrm{CD}$, Chillemi G, et al. Home-prepared hamburger and Sporadic Hemolytic Uremic Syndrome, Argentina. Emerg Infect Dis 2003; 9: 11841186.

Wells JG, Shipman LD, Greene KD, Sowers EG, Green JH, Cameron DN, et al. Isolation of Escherichia coli serotype 0157:H7 and other Shigalike toxin-producing E. coli from dairy cattle. J Clin Microbiol. 1991; 29: 985-989.

World Health Organization, Food Safety Unit Consultations and Workshops. Prevention and control of enterohaemorrhagic Escherichia coli (EHEC) infections. Report of a WHO consultation; Geneva, Switzerland; 199728 Apr-1 May. Geneva: The Organization; 1997. Report No.: WHO/FSF/FOS/97.6. 